\title{
Soluble adhesion molecules in pre-clinical Type 1 diabetes: a prospective study
}

\author{
A. M. Toivonen ${ }^{1}$, P. Kulmala ${ }^{2}$, K. Savola ${ }^{2}$, H. K. Åkerblom ${ }^{3}$, M. Knip ${ }^{1,3}$, \\ the Childhood Diabetes in Finland Study Group \\ ${ }^{1}$ Medical School, University of Tampere and Department of Paediatrics, Tampere University Hospital, Tampere, Finland \\ 2 Department of Paediatrics, University of Oulu, Oulu, Finland \\ ${ }^{3}$ Hospital for Children and Adolescents, University of Helsinki, HUCH, Helsinki, Finland
}

\section{Diabetologia (2003) 46:492-495}

The affiliation corresponding to the authors H. K. Åkerblom and M. Knip is missing in the printed article. The correct affiliations of the authors are as follows:

A. M. Toivonen ${ }^{1}$, P. Kulmala ${ }^{2}$, K. Savola ${ }^{2}$, H. K. Åkerblom ${ }^{3}$, M. Knip ${ }^{1,3}$,

the Childhood Diabetes in Finland Study Group

${ }^{1}$ Medical School, University of Tampere and Department of Paediatrics, Tampere University Hospital, Tampere, Finland

2 Department of Paediatrics, University of Oulu, Oulu, Finland

${ }^{3}$ Hospital for Children and Adolescents, University of Helsinki, Helsinki, Finland
DOI 10.1007/s00125-003-1279-1

Published online: 20 November 2003

C) Springer-Verlag 2003

The online version of the original article can be found at http://dx.doi.org/10.1007/s00125-003-1072-1

M. Knip MD PhD (凶), Hospital for Children and Adolescents, University of Helsinki, P.O. Box 281, 00029 HUCH, Helsinki, Finland

E-mail: Mikael.Knip@hus.fi

\section{Evaluation of the new ADA and WHO criteria for classification of diabetes mellitus in young adult people (15-34 yrs) in the Diabetes Incidence Study in Sweden (DISS)}

\author{
H. Borg ${ }^{1,8}$, H. J. Arnqvist ${ }^{2}$, E. Björk ${ }^{3}$, J. Bolinder ${ }^{4}$, J. W. Eriksson ${ }^{5}$, L. Nyström6 ${ }^{6}$ J-O. Jeppsson ${ }^{7}$, G. Sundkvist ${ }^{1}$ \\ ${ }^{1}$ Department of Endocrinology, Malmö University Hospital, Malmö, Sweden \\ 2 Department of Internal Medicine, Faculty of Health Science, Linköping, Sweden \\ ${ }^{3}$ Department of Medicine, University Hospital, Uppsala, Sweden \\ ${ }^{4}$ Department of Internal Medicine, Huddinge Hospital, Huddinge, Sweden \\ 5 Department of Medicine, University hospital, Umeå, Sweden \\ ${ }^{6}$ Epidemiology Department of Public Health and Clinical Medicine, Umeå University, Umeå, Sweden \\ ${ }^{7}$ Department of Clinical Chemistry, Malmö University Hospital, Malmö, Sweden \\ 8 Wallenberg Laboratory, Entrance 46 2nd floor, Malmö University Hospital, Malmö, Sweden
}

\section{Diabetologia (2003) 46:173-181}

Within Figure 3 under the heading "Type I", "ab$n=33$ " at diagnosis $n=29$ should remain "ab-" at follow-up and not "ab+".
DOI 10.1007/s00125-003-1282-6

Published online: 16 December 2003

C Springer-Verlag 2003

The online version of the original article can be found at http://dx.doi.org/10.1007/s00125-002-1021-4

Dr. H. Borg ( Wallenberg Laboratory, Entrance 46 2nd floor, Malmö University Hospital, 20502 Malmö, Sweden E-mail: Henrik.Borg@endo.mas.lu.se 